\title{
Possibility of employing a small power tangential flow turbine prototype in a micro solar concentration plant
}

\author{
Mario Amelio, Silvio Barbarelli*, Francesco Rovense, Nino M. Scornaienchi \\ Department of Mechanical, Energy and Management Engineering, University of Calabria, Ponte P. \\ Bucci Street, Cube 44/C, Rende I87036, Italy \\ Email: silvio.barbarelli@unical.it
}

\begin{abstract}
This article describes a hypothetical use in a micro solar plant of a small power tangential flow turbine prototype, built and tested at the Department of Mechanical, Energy and Management Engineering (DIMEG) of the University of Calabria.

The turbine prototype has the ability to recover efficiently energy from small sources, better than other turbines of the same size, in a wide set of operating conditions and power operations, having the possibility to regulate the flow rate without excessive losses.

The micro solar powered central unit is conceived with Parabolic Trough Collectors (PTCs): the vapor pressure analysis extends from 5 to 25 bar, while the inlet turbine temperatures considered are included in the range from 180 to $283{ }^{\circ} \mathrm{C}$.

Steam pressure at the turbine discharge has been set to 1 bar, simplifying so the plant complexity and making possible CHP generation. The solar field has been dimensioned, for each of the cases examined, in relation to the rated operating temperature and steam flow rate supplying the turbine.

Finally, the last 25 bar configuration has been analyzed in more detail by extrapolating the annual energy output and the average efficiency of the overall cycle, also considering the cogeneration contribution.
\end{abstract}

Keywords: Solar Plant, Small Turbine Prototype, Design Criteria, Mirror Field, Case Study.

\section{INTRODUCTION}

Conversion to mechanical power of thermal waste energy or heat, produced in plants that use fuels from waste, biofuels or solar energy, is particularly convenient for economic and environmental reasons [1]. Similar plants, having nominal sizes between 10 and $300 \mathrm{~kW}$, are particularly interesting because they are able to exploit small energy resources and to easily integrate them into distributed generation systems, in which intelligent management amalgams and organizes the availability of multiple heterogeneous sources.

Among the above-mentioned thermal resources, solar heat obtained from direct radiation is valuable for the high temperature that can be reached through concentrating mirrors.

There are several methods for the collection and conversion of solar radiation. Most important are currently: Compound Parabolic Collectors (CPCs), Linear Fresnel Reflectors (LFRs), Parabolic Dish Collectors (PDCs), Heliostat Field Collectors (HFCs), Parabolic Through Collectors (PTCs), widely described in literature [2-3]. The steam production by PTCs was tested for first time in Plataforma solar de Almeria in Spain, and is now under successful commercial stage [4].

In CSPPs (concentrate solar power plants) the solar system section represents a relevant amount of the total plant installation costs which strongly depend on plant configuration and size [5].

In such a case, even if the cost per square meter is higher, the high concentration ratio and, therefore, the higher maximum temperature of the heat transfer fluid (HTF) leads to an increase of the engine section efficiency, making the plant more compact.

Plant layouts suitable for off-grid power can be divided in two main categories based on HTF maximum temperature: medium temperature plants (up to $500{ }^{\circ} \mathrm{C}$ ) and high temperature plants (above $500^{\circ} \mathrm{C}$ )

This stimulates attention to steam turbines, for the good match between their operating temperatures and those of the source, besides the very good adaptability in combined heat and power plants. However, it is well known that small steam turbines would have limited performance if realized with a scaling down of high power axial machines.

In fact, when the nominal flow rates are less than $1 \mathrm{~kg} / \mathrm{s}$, the performance of these machines is limited, for the very small dimensions of the blades. Another critical aspect arises when power changing is done by lowing the partial admission annulus degree, consequently to the small flow required. In this case, the fluid dynamic losses can lower the efficiency to values of the order of $30 \%$ if the annulus degree is about $25 \%$ 
[6].

It is well known that it is not possible to transfer design criteria usually adopted for traditional machines to a small steam turbine: efficiency would be reduced to unacceptable levels. For smaller machines, therefore, unconventional shapes are adopted [7].

Unfortunally, under the power of $100 \mathrm{kWel}$, there are not many efficient solutions [8]. These difficulties have also led to alternative solutions like steam screw expanders, though their nominal power still exceeds $100 \mathrm{~kW}$. [9-10].

With the aim to cover efficiently the niche of power above mentioned, an impulse turbine prototype, with an innovative design and a very small rated power, has been designed and studied at the Department of Mechanical, Energy and Management Engineering (DIMEG) of the University of Calabria (UNICAL) [11-13].

This type of turbine does not work at high rotational speeds and can be built with inexpensive materials. It can also process fluids of different nature.

Some peculiarities of the machine make it more functional at low flow rates, where it is also appreciated for its adaptability to variable flow conditions. This makes it suitable for the employment in small steam energy systems (from few $\mathrm{kW}$ up to hundreds of $\mathrm{kW}$ ). For example, for the conversion of heat produced in small steam generators fired by biofuels, or of those discharged from the topping cycle of a combined micro plant [14].

Even more advantageous is its management in cogeneration systems, especially if it is integrated in smart grids, for the distributed generation, or when the primary source exploited is the heat of the sun.

In this work, first, the turbine is briefly described, hence, an estimate of the energy yield of thermodynamic solar systems is performed, by considering the possibility to use it in a multi-stages configuration. The solar energy harvesting is considered through linear parabolic concentrators (PTC) able to produce steam flow.

It is worth pointing out that this is a preliminary assessment based solely on the experience deduced by the single-stage turbine measurements, and on a parametric thermodynamic analysis, without any economic consideration.

All the stages of the machine necessary to convert the whole available enthalpy drop, have the same prototype efficiency. Solar field has been calculated using data of Seville (Spain), while the design of collectors, as well as the cycle performance have been evaluated by using the Thermoflex code.

In order to obtain a simple plant, as good practice suggests for small size systems, a thermodynamic cycle with only one superheating, considering maximum pressures of $5,10,15$, 20 , and 25 bar and atmospheric discharge pressure has been studied. This latter option simplifies condensation, eliminates the degasser and, nonetheless, causes the discharged heat to be a resource available to meet thermal needs.

\section{METHODOLOGY}

\subsection{Turbine prototype}

The turbine typology conceived at the DIMEG of UNICAL, can be synthesized as a single stage, tangential flow turbine having a rotating channel [11-13] dug on the rotor periphery in which one or more deflector ducts are inserted. It is a turbine type able to process small flow rates (of the order of hundreds of grams per second) and, therefore, small powers (in the order of tens of $\mathrm{kWs}$ ).

Moreover, it is suitable to recover discharged flows, as exhausted gas, or low enthalpy steam, but it can work also with air.

The flow is supplied by a nozzle with a variable throat area, whose changes are determined by a moving spear and expressed by the $K_{p}$ parameter (nozzle area / area of the transversal section of the rotating channel). The fluid accelerates into the nozzle, flows into the rotating channel, and finally, through the deflectors, axially discharges into the stator casing, as shown in the scheme of Fig. 1.

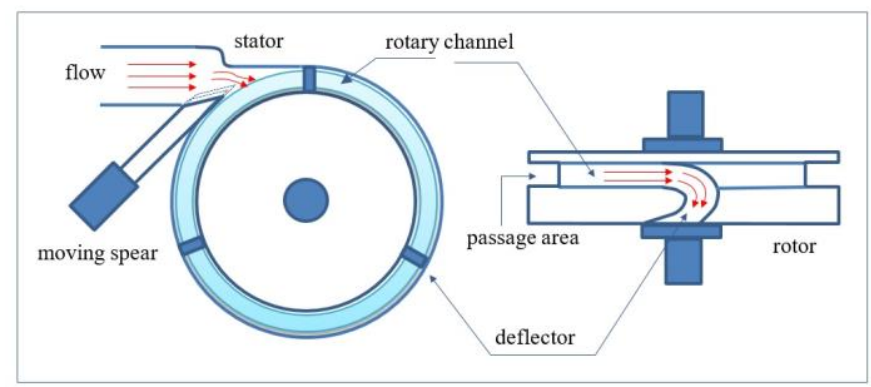

Figure 1. Turbine layout

Several prototypes were built and tested both with air and with superheated steam at the Turbomachinery Laboratory of the DIMEG with 1, 3, 5 and 7 deflectors ducts [12] and with different diameters of $0.18,0.3$ and $0.4 \mathrm{~m}$.

Figure 2 shows one of the prototypes built with 5 deflectors, highlighting the stator-rotor coupling.

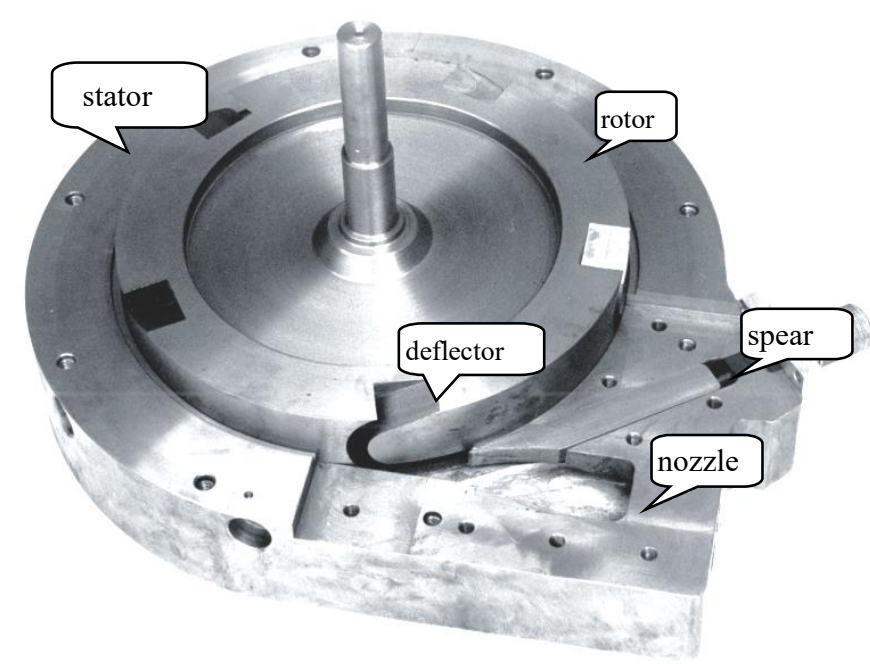

Figure 2. Turbine prototype

Compared to micro turbines [15] of the same size, its particular design has the advantage of eliminating losses due to the excessive partial admission annulus degree and to the small blade passages dimensions, which in traditional axial turbines are necessary to guarantee extremely low flow rates. Moreover, the turbine prototype efficiency is little variable, in a wide set of operating conditions.

For example, the above illustrated prototype, tested with compressed air at environment temperature, at a rotational regime to $9000 \mathrm{rpm}$ and with feeding pressure $p_{o}$ of 4 bar, reaches efficiencies higher than $36 \%$ by changing the flow 
rate from 120 to $280 \mathrm{gr} / \mathrm{sec}$, and, consequently, the power from 4.36 to $10.18 \mathrm{~kW}$, as shown in Fig. 3

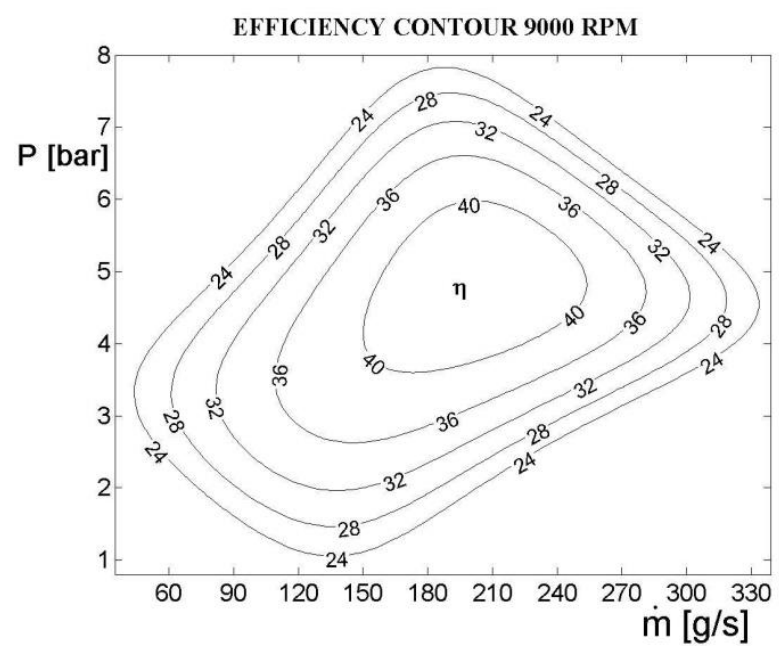

Figure 3. Efficiency contour curves

Figure 4 shows the experimental efficiency curves [13] of the 5-deflectors turbine prototype, obtained by changing the $K_{p}$ parameter - related to the flow rate - for different velocity ratios $u / c_{o}$ and feeding pressures $p_{o}$ which, considering an atmospheric discharge pressure, coincide with the expansion ratio $\beta$.

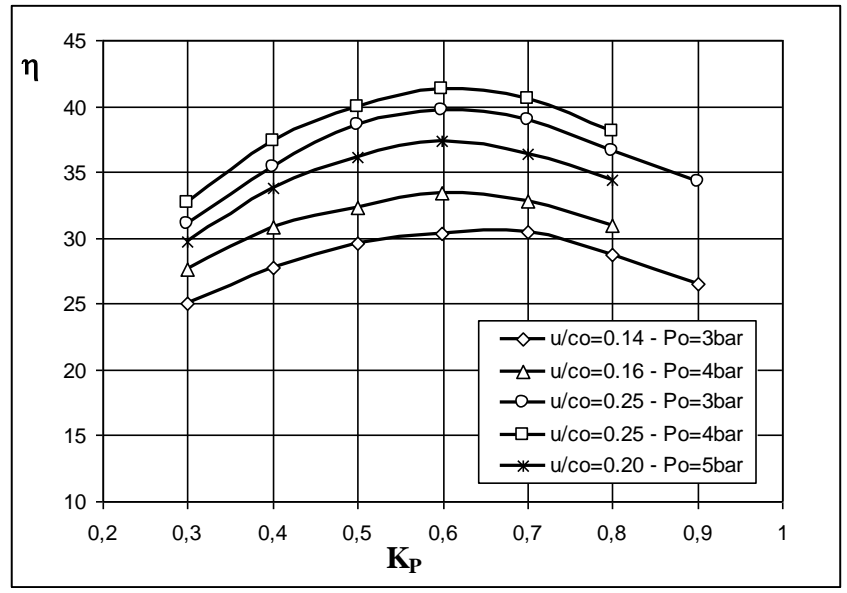

Figure 4. Efficiency curves by changing the opening spear coefficient $K_{p}$, at different feeding pressures and velocity ratios.

It can be noticed that the maximum efficiencies get about $60 \%$ of throat opening $\left(K_{p}\right)$ for all the expansion ratios considered and that, on the other hand, the maximum efficiency value achieved is $43 \%$ at the feeding pressure of 4 bar, and for velocity ratio $u / c_{o}$ of 0.25 .

In a later version of the prototype, equipped with 5 nozzles and 5 deflectors and tested at the same operating conditions, maximum efficiencies of about $50 \%$ were recorded.

In the present work, the authors illustrate the possibility to combine the turbine typology developed with a solar plant, whose features are determined by changing the maximum feeding pressures up to 25 bars. Consequently, based on the experience gained in this field, prototypes are designed with one, two or more stages (turbine cascade).

\subsection{Plant description}

The entire plant layout analyzed in this work is illustrated in figure 5. It is composed by the solar field system (SFs) (1), the turbine cascade (2), the electric generator (3), the water condenser or the heat exchanger for cogeneration (4) and the recirculation pump (5).

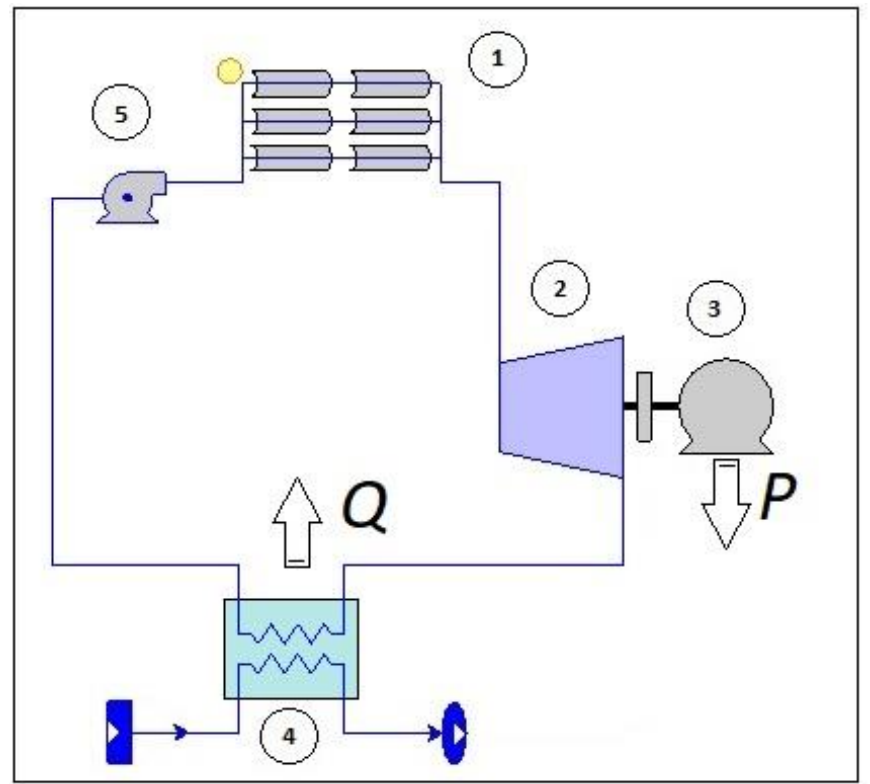

Figure 5. Solar plant layout

The elements composing the solar field are parabolicthrough collectors (PTC); in more detail, they are constituted by the reflective surface, the receiver tube, where the working fluid flows, the tracking system and the collector support.

The cycle begins when the solar radiation heats the absorbed tube, crossed from the heat transfer fluid. In the final segment of the parabolic through (1) the water changes its phase, becoming steam.

In order to avoid the possibility of water injection in the turbine, a water separator has to be installed between the solar collector and power block.

The steam, formed in PTCs, feeds the turbine (2), producing so electrical power $P$ by means of the generator (3) The nominal enthalpy condition, as well as the temperature and pressure of the steam entering in the turbine are determined by the solar field size (mirrors area)

These operating conditions, obviously, change continuously depending of the solar radiation, sun position etc.

Thus, when the nominal conditions cannot be met, a reduction of the steam flow is activated by the movable spear shown in Fig. 2, relying on the ability of the turbine to accommodate a wide range of steam flow rates.

On the other hand, when the solar radiation, is higher than the design one, because no storage present, a percentage of reflective area is defocused.

The steam outgoing from the turbine is all condensed in the water condenser (4), cooled by water too.

By the way, it is possible to recover the thermal power. $\dot{Q}=\dot{m} \Delta h$ through a heat exchanger specially designed for cogeneration.

Finally, feedwater pump (5) provide to increase the pressure of the condensate to the beginning condition, and the cycle restarts. 


\subsection{Design criteria of the cascade turbine}

It is now considered the possibility to employ the steam flow produced from the solar field, in one or more turbine prototype, depending on the flowing conditions.

The various plant configurations take into account increasing solar field dimensions, increasing steam flow temperature and pressure, and consequent increasing number of turbine stages.

The design of each turbine is done, by following the experience matured in the field.

So, by referring to Fig. 4, it is known that the best work conditions result at opening spear coefficient $K_{p}=0.6$, pressure expansion ratio $\beta=4$ and velocity ratio $u / c_{o}=0.25$.

These data are useful to design the turbine cascade necessary to employ efficiently the high enthalpy drop coming from the solar field.

Now in Fig. 6, a way to split in more stages the available enthalpy drop, is illustrated.

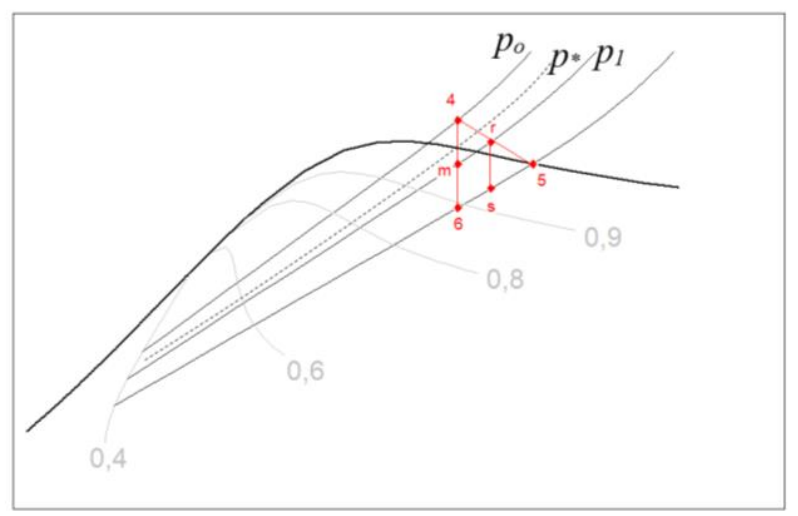

Figure 6. Split of the enthalpy drop criteria

In Fig. 6, for simplicity, two stages are considered, but the discourse can by generalized at a greater number of stages. The various points appearing in the figure represent respectively:

- point 4: starting of the expansion of the cascade turbine;

- $\quad$ point 5: end of the expansion of the cascade turbine on the saturation curve at atmospheric pressure;

- point 6: end of the isentropic expansion of the cascade turbine in the wet region;

- $\quad$ point $\mathrm{m}$ : obtained by splitting the total enthalpy drop in equal parts around $200 \mathrm{~kJ} / \mathrm{kg}$;

- $\quad$ point $r$ : end of the expansion of the first turbine stage;

- point s: end of the isentropic expansion of the second turbine stage.

Starting from the maximum value of temperature and pressure - point 4 of Fig. 4 -, a discharge at atmospheric pressure on the saturation curve - point 5 of fig. 4 - is considered. The values of enthalpy and entropy of the triangle 4-5-6, related to the overall turbines cascade, are determined by considering an efficiency of the turbine stages equal to $50 \%$ (maximum value reachable by of the turbine prototype at best conditions).

$\eta=\frac{\Delta h_{45}}{\Delta h_{46}}=0.5$
The fractioning of the enthalpy drop is done by considering the optimal expansion ratio, which is around $3 \div 4$, implying maximum enthalpy drop for each stage of the order of 200 $\mathrm{kJ} / \mathrm{kg}$ or slightly more.

For this reason, the feeding pressure of each stage is calculable directly on the h-s chart, by splitting the total enthalpy drop in $n$ stage as it follows: the value $n^{*}$ obtained by eq. 2 , is rounded to the integer $n$, useful to determine the actual enthalpy drop of the single stage $\left(\Delta h_{i_{s} \text { stage }}\right)_{i}$ (eq. 3$)$.

$n^{*}=\frac{\Delta h_{t o t}}{200}$

$\left(\Delta h_{i s_{-} \text {stage }}\right)_{i}=\frac{\Delta h_{t o t}}{n}$

From the h-s chart it is so possible to find the pressure $p_{i+1}$ at the discharge of the $i^{\text {th }}$ turbine stage and then to evaluate, by knowing the isentropic enthalpy drop $\Delta h_{\text {is stage, the }}$ pressure ratio $\beta_{i}$, which is desirable to be equal around 4 .

Once defined the fluid dynamic conditions it is possible to determine the main geometrical parameters of the turbine stages.

Taking into account the best $\mathrm{u} / \mathrm{c}_{\mathrm{o}}$ value of $0.25\left(k_{o p t}\right)$, and by considering a 10000rpm rotation regime, it is possible to determine the diameter of each turbine stage as:

$D_{r o t}=\frac{60 u}{\pi n}$

where $u$ is given by:

$u=k_{\text {opt }} c_{o}=0.25 c_{o}=0.25 \sqrt{2 \Delta h_{\text {is_stage }}}$

The power of the first (head) stage of the turbine cascade is fixed to $5 \mathrm{~kW}$. This allows calculating the steam flow rate, which is provided by:

$\dot{m}=\frac{P_{\text {head }}}{\eta_{\text {turb }} \Delta h_{\text {is_stage }}}$

Once fixed the flow rate, it is possible to calculate the throat area $\left(A_{T H}\right)$ of the turbine tangential nozzle of each $i^{\text {th }}$ stage as:

$\left(A_{T H}\right)_{i}=\frac{\dot{m}}{\left(\rho_{t h} c_{t h}\right)_{i}}$

The values of density $\rho_{t h}$ and velocity $c_{t h}$ of the steam can be calculated by knowing, from the experience, that the flow reaches sonic condition at the nozzle throat (choked flow [11]). So, the throat pressure is given by:

$p^{*}=p_{i}\left(\frac{2}{k+1}\right)^{\frac{k}{k-1}} \approx 0.55 p_{i} \quad(\mathrm{k}=1.3)$

being $p_{i}$ the feeding pressure of the $\mathrm{i}^{\text {th }}$ stage. 
Consequently, the density is found on the h-s chart and the flow velocity is obtained by converting to kinetic energy the isentropic enthalpy drops $\Delta h^{*}$ of the nozzle as follows:

$c^{*}=\sqrt{2 \Delta h_{t h}^{*}}$

The throat area from (7) is not the maximum area of the nozzle, but it represents the $60 \%$ of the full value, by considering the optimal value of the $K_{p}$ parameter, resumed from the experience (see Fig. 4)

Therefore, the channel area is calculated equal to the maximum opening of the nozzle, i.e.:

$\mathrm{A}_{\mathrm{CH}}=\mathrm{A}_{\mathrm{TH}} / 0.6$

while the height $h$ and width $b$ of the cross-passage section in the rotary channel are obtained by fixing the ratio $h / b$ equal to 2.

The main fluid dynamical and geometrical parameters considered for the turbine cascade design are summarized in table 1 .

Table 1. Main turbine cascade parameters

\begin{tabular}{ccc}
\hline velocity ratio $\left(k_{\text {opt }}\right)$ & $u / c_{o}$ & 0.25 \\
\hline opening spear coefficient & $K_{p}$ & 0.6 \\
\hline Maximum efficiency & $\eta_{\max }$ & $50 \%$ \\
\hline Minimum size of the throat & $b$ & $4 \mathrm{~mm}$ \\
\hline Rotational speed & $n$ & $10000 \mathrm{rpm}$ \\
\hline Maximum feeding pressure & $p_{o}$ & $25 \mathrm{bar}$ \\
\hline $\begin{array}{c}\text { Maximum feeding } \\
\text { Temperature }\end{array}$ & $T_{o}$ & $280{ }^{\circ} \mathrm{C}$ \\
\hline Maximum expansion ratio & $\beta$ & 4 \\
\hline Maximum enthalpy drop & $\Delta h_{\max }$ & $200 \mathrm{~kJ} / \mathrm{kg}$ \\
\hline Head turbine power & $P_{\text {head }}$ & 5 \\
\hline
\end{tabular}

\subsection{Simulations}

In order to evaluate the behavior of the turbine prototype working in the solar cycle above described, several simulations have been done by means of the Thermoflex code.

This code is able to evaluate the solar plant parameters, like the mirrors area, the receiver tube diameter as well as the radiative and convective losses $Q$ ".

The values of pressure and temperature of the flow entering in the turbine are the same of the flow outgoing from the solar collectors in superheated steam conditions.

The power absorbed by collector has been evaluated as:

$Q_{a b s}^{\prime}=A N I \eta_{o p t} A$

where:

- $A N I$ is the Aperture Normal Irradiance established from inputs of $D N I$ (Direct Normal Radiation);

- $\eta_{\text {opt }}$ is the optical efficiency of the solar field;

- $A$ is the reflective area;

The optical efficiency is expressed as:

$\eta_{\text {opt }}=\eta_{\text {nom }} f_{\text {inc }} f_{\text {clean }} f_{\text {loss }}$

where:

- $\quad \eta_{\text {nom }}$ is the nominal efficiency
- $\quad f_{\text {incident }}$ is the incident angle correction factor

- $f_{\text {clean }}$ is the cleanliness factor

- $f_{\text {loss }}$ is the end loss factor

The losses $Q$ ” are function of diameter receiver tube, surface temperature and mass flow rate of working fluid through the receiver.

Taking into account eq. 1 and computing the above cited heat losses, the net power absorbed by the heat transfer fluid is then evaluated as:

$Q_{N e t}=Q^{\prime}-Q^{\prime \prime}$

The software Thermoflex, by referring to steady state condition, evaluates the absorbed power $Q^{\prime}$ as function of Azimuth and Zenith.

In the present simulations, a value of the Solar Multiple (SM) equal 1 has been considered, because no storage is used

To obtain the energy production, as well as the annual average efficiency, typical 30-years meteorogical data (TMY3) of Seville town have been used [16].

Particularly the yearly data of ambient air, relative humidity, DNI, Azimuth and Zenith, with hourly step has been employed to characterize the solar collector. For each hour, the code, by Azimuth and Zenith, evaluates the optical efficiency expressed by equation 12 , while by DNI calculates the ANI and the losses.

By these data, the power absorbed by the solar field, and the gross power have been calculated, and finally the yearly energy production and the average efficiency have been evaluated.

The DNI data with a value less than $100 \mathrm{~W} / \mathrm{m}^{2}$ has not considered for the input simulation.

In the next section, different system configurations are taken into consideration, with the maximum pressure coming from the solar field, ranging from 5 to 25 bars. For each configuration, the cascade turbine was designed, evaluating the power and efficiency of the system, trying to show the consequences on the complexity of the various components (turbines plus solar field).

\section{RESULTS}

\subsection{Investigation of the potentiality of the turbine by changing the feeding pressure}

Table 2. Plant parameters variation by changing the admission pressure

\begin{tabular}{cccccc}
\hline $\begin{array}{c}\text { Admission pressure } \\
\text { [bar] }\end{array}$ & 5 & 10 & 15 & 20 & 25 \\
\hline $\begin{array}{c}\text { Discharge pressure } \\
\text { [bar] }\end{array}$ & 1 & 1 & 1 & 1 & 1 \\
\hline $\begin{array}{c}\text { Admission } \\
\left.\text { temperature [ }{ }^{\circ} \mathrm{C}\right]\end{array}$ & 181.5 & 222.1 & 248.3 & 267.3 & 283.0 \\
\hline Stages number & 1 & 2 & 2 & 3 & 3 \\
\hline Flow rate [kg/s] & 0.041 & 0.06 & 0.05 & 0.057 & 0.059 \\
\hline Cycle efficiency & $5.9 \%$ & $8.3 \%$ & $9.7 \%$ & $10.7 \%$ & $11.5 \%$ \\
\hline $\begin{array}{c}\text { Power of the } \\
\text { cascade [kW] }\end{array}$ & 5 & 10.3 & 10.3 & 15.7 & 15.8 \\
\hline $\begin{array}{c}\text { Electrical power } \\
\text { [kW] }\end{array}$ & 4.7 & 9.66 & 9.70 & 14.80 & 14.85 \\
\hline Mirrors area [m ${ }^{2}$ ] & 193 & 290.5 & 250.8 & 306.3 & 304.4 \\
\hline Plant efficiency & $3.88 \%$ & $5.49 \%$ & $6.42 \%$ & $7.06 \%$ & $7.54 \%$ \\
\hline $\begin{array}{c}\text { Thermal power } \\
\text { available [kW] }\end{array}$ & 92 & 126.3 & 106.5 & 143.7 & 133.4 \\
\hline
\end{tabular}


In order to explore various system configurations, trying to optimize the energy output - plant complexity ratio, maximum admission pressures of $5,10,15,20,25$ bar were considered, while the pressure at discharge was fixed to 1 bar (atmospheric value). Table 2 lists the main system parameters calculated, i.e. the maximum operating temperature, the number of stages needed to get the total enthalpy drop, the steam flow rate produced by mirrors, the thermodynamic cycle efficiency, the electrical power generated, the mirrors area required as well as global plant efficiency.

Moreover, the table reports the thermal power that can be recovered by the saturated steam at the exit of the turbine cascade.

As illustrated in Table 2, by increasing the maximum pressure, the efficiency of the thermodynamic cycle increases, but paying anyway the prize of a greater plant complication. In fact, both the number of stages and the steam flow rate increases, as well as the power of the turbine cascade. At a pressure of 25 bar, a total plant efficiency of $7.5 \%$ and a total electric power of $15.8 \mathrm{~kW}$ are achieved, but it is necessary, to consider a mirror area of $304 \mathrm{~m}^{2}$ and a number of stages equal to 3. Anyway, in this case it is possible to recover a thermal power for cogeneration purpose equal to $133.4 \mathrm{~kW}$.

The next figure (Fig. 7) illustrates this last configuration, by highlighting how the steam expansion in the h-s chart, is elaborated by a 3 -stage turbine cascade. The first turbine stage, which receives the steam flow rate of $59 \mathrm{gr} / \mathrm{sec}$ at the pressure of 25 bar, discharges it at the pressure of 10 bar, successively, the second turbine stage discharges this steam flow at the subsequent pressure of 3.4 bar and, finally, the third and last stage discharges it at atmospheric pressure.

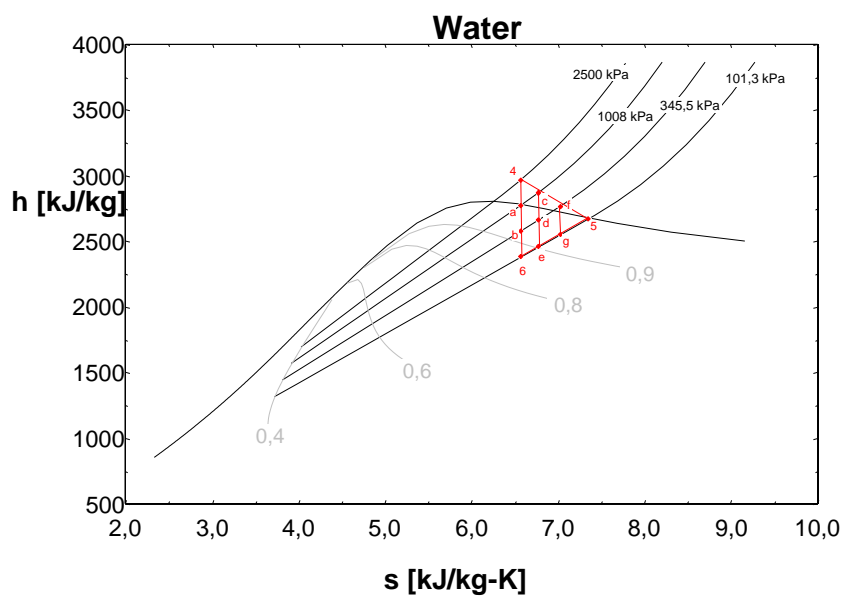

Figure 7. Expansion in h-s plane at maximum working pressure of 25 bar and discharge pressure of 1 bar

Table 3 reports the main design parameters of the 3 turbine stages: by considering a rotational regime of $10000 \mathrm{rpm}$ the rotors diameters are of about $0.3 \mathrm{~m}$, while the throat size increases, taking also into account the higher specific volume of the steam got at lower pressures.

The isentropic enthalpy drop is of the order of $200 \mathrm{~kJ} / \mathrm{kg}$ (design values) implying Mach numbers slightly higher than 1 in the rotary channel (transonic conditions); this reduces the entity of the shock waves in the deflector ducts, happening for accomplishing the right value of pressure at discharge of the turbine stage.
Table 3. Design turbines parameters

\begin{tabular}{cccc}
\hline Turbine stage & 1 stage & 2 stage & 3 stage \\
\hline Rotational speed & 10000 & 10000 & 10000 \\
\hline Power & 5 & 5.3 & 5.5 \\
\hline Rotors diameter $[\mathrm{m}]$ & 0.3 & 0.31 & 0.31 \\
\hline Throat size $[\mathrm{mm}]$ & 4.4 & 7 & 11 \\
\hline $\begin{array}{c}\text { isentropic enthalpy drop } \\
{[\mathrm{kJ} / \mathrm{kg}]}\end{array}$ & 194.4 & 206.5 & 212.6 \\
\hline $\begin{array}{c}\text { Mach Number at end- } \\
\text { expansion conditions }\end{array}$ & 1.2 & 1.3 & 1.4 \\
\hline
\end{tabular}

In the following section, a case study contemplating this cascade turbine configuration is presented.

\subsection{Case study}

The case study is referred to the of Seville town.

Firstly, the plant performances related to a classical sunny day (without clouds), in terms of hourly power production and efficiency are evaluated.

The overall efficiency considered in the present analysis is expressed by the follow equation:

$\eta_{o v}=\frac{P_{e l}}{P_{a b s, S F}}$

where:

- $\eta_{o v}$ is the overall efficiency;

- $P_{e l}$ is the gross electric power;

- $P_{a b s, S F}$ is the net power absorbed by the solar field

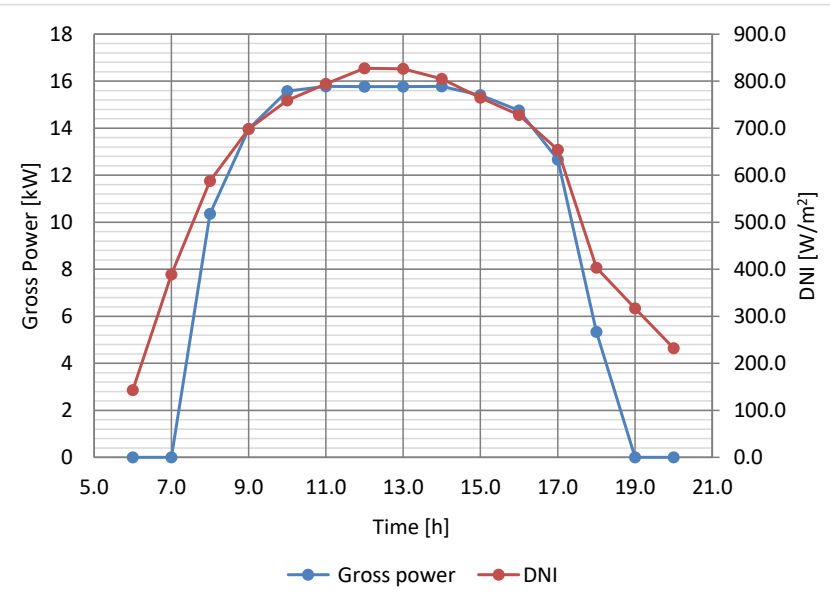

Figure 8. Gross power trend and DNI vs hours of a typical summer sunny day

Figure 8 shows the DNI (red line) and the gross power (turbine cascade shaft power - blue line) changes during a typical summer sunny day.

Before 10.00 AM and after 15.00, a focusing of all parabolic concentrators and a steam flow rate adjustment is operated in order to gain the peak power of the plant, while the DNI is lower than the design one.

It is possible to observe that the power trend follows the DNI. Particularly, during middle day hours, the power is constant while the DNI increases. The reason is imputable to the defocusing of a part of reflective area, because the DNI design $\left(800 \mathrm{~W} / \mathrm{m}^{2}\right)$ has been overcome. 


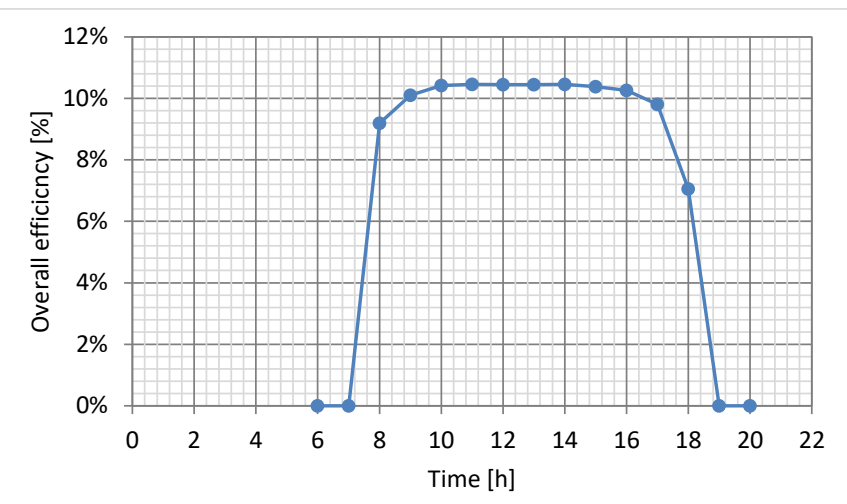

Figure 9. Plant overall efficiency vs hours of the considered day

Figure 9 shows the overall efficiency hourly changes of the considered day. An efficiency value around $10 \%$ results, during all the operating hours. Then, during clear days, the plant could operate 10 hours with a considerable efficiency.

Table 4 resumes the result of the annual energy estimation together with the average efficiency, both considering or not thermal power recovering (cogeneration).

Table 4. Simulations result

\begin{tabular}{cc}
\hline Annual electric energy [MWh] & 25.6 \\
\hline Capacity factor & $18 \%$ \\
Operating hours [hours per year] & 1600 \\
Average electric efficiency & $9 \%$ \\
Usable thermal energy (cogeneration) [MWh] & 180 \\
Average Thermal efficiency & $70 \%$ \\
Total system efficiency & $79 \%$ \\
\hline
\end{tabular}

The results show as the plant could operate successfully around 1600 hours, by producing 25.6 MWh of electricity and $180 \mathrm{MWh}$ of thermal energy, obtained by multiplying the thermal power available from Table 2 for the equivalent operating yearly hours and considering a recovering efficiency of 0.85 .

These values could increase by increasing the Solar Multiple.

The overall efficiency is acceptable ( $9 \%$ ), considering a small scale Rankine cycle employed, and it increases up to $79 \%$ if the plant combines cogeneration purpose [17-18].

\section{CONCLUSIONS}

The possibility of employing a small compressible fluid turbine prototype in a micro solar plant using Parabolic through collectors (PTC) has been analysed. Five plant solutions were theoretically evaluated by increasing the pressure of the steam produced by the parabolic concentrators from 5 to 25 bars.

The performance results are encouraging, considering the very small size of the plant, which, in the best configuration, is conceived with a maximum steam pressure of 25 bar and a discharge pressure of 1 bar, implementing a turbine cascade of 3 stage having a nominal power of $15 \mathrm{~kW}$.

In fact, the result of the calculation shows that the plant would be able to produce $25.6 \mathrm{MWh}$ of electricity and 180 MWh of thermal energy, with an average efficiency of $9 \%$ in absence of cogeneration and a total system efficiency of $79 \%$ if, instead, the heat discarded is recovered for covering a thermal need.

Indubitable advantage of the turbine prototype considered, is the ability to process small steam flow rates in a wide set of operating conditions. That is very important if changeable weather conditions are considered, giving so the possibility to export the presented technology to heterogeneous geographic locations, characterized by different climates.

\section{REFERENCES}

[1] Nastasi B., Lo Basso G. (2017). Power-to-gas integration in the transition towards future urban energy systems, International Journal of Hydrogen Energy, Vol. 42, No. 38, pp. 23933-23951. DOI: 10.1016/j.ijhydene.2017.07.149

[2] Winter C.J., Sizmann R.L., Vant-Hull L.L. (1991). Solar Power Plants. Ed. Springer-Verlag. DOI: 10.1007/978-3-642-61245-9

[3] Heliofocus web site, http://www.heliofocus.com, last access 16/06/2015.

[4] Internet source available from: http://www.psa.es/es/index.php

[5] IRENA. (2015). Renewable Power Generation Costs in 2014, International Renewable Energy Agency.

[6] Horlock J.H. (1973). Axial Flow Turbines: Fluid Mechanics and Thermodynamics, Krieger Pub. Co.

[7] Bracco S., Delfino F. (2017). A mathematical model for the dynamic simulation of low size cogeneration gas turbines within smart microgrids, Energy, Vol. 119, pp. 710-723. DOI: $10.1016 /$ j.energy.2016.11.033

[8] Weiss A.P., Zinn G. (2016). Micro turbine generators for waste heat recovery and compressed air energy storage, Proceedings of 15th conference on Power System Engineering, Thermodynamics \& Fluid Flow ES 2016, Pilsen, Czech Republic.

[9] Li P., Li J., Gao G., Pei G., Su Y., Ji J., Ye B. (2017). Modeling and optimization of solar-powered cascade Rankine cycle system with respect to the characteristics of steam screw expander, Renewable Energy, Vol. 112, pp. 398-412. DOI: 10.1016/j.renene.2017.05.054

[10] Kuwubara H., Nishimura M., Matsukuma M., Matsui T. (2010). Micro steam energy generator, KOBELCO Technology Review, pp. 16-22.

[11] Barbarelli S., Florio G., Scornaienchi N.M. (2017). Theoretical and experimental analysis of a new compressible flow small power turbine prototype, International Journal of Heat and Technology, Vol. 35, Special Issue 1. DOI: 10.18280/ijht.35Sp0153

[12] Scornaienchi N.M., Florio G., Belli M. (1994). A Small power turbine characterized by a tangential flux within a rotating channel, Proceedings of Second Biennal European Conference on Engineering System \& Analysis, Vol. 64-68, pp. 511-518.

[13] Barbarelli S., Florio G., Scornaienchi N.M. (2005). Performance analysis of a low-power tangential flow turbine with rotary channel, Journal of Energy Resources Technology, Transactions of the ASME, Vol. 127, No. 4, pp. 272-279. DOI: $\underline{10.1115 / 1.1944008}$

[14] Amirante R., Coratella C., Distaso E., Tamburrano P. (2015). A small size combined system for the 
production of energy from renewable sources and unconventional fuels, Energy Procedia, Vol. 81, pp. 240-248. DOI: 10.1016/j.egypro.2015.12.090

[15] Chul K.K., Joon Y.Y. (2016). Performance analysis of bladeless jet propulsion micro-steam turbine for microCHP (combined heat and power) systems utilizing low-grade heat sources, Energy, Vol. 101, pp. 411-420. DOI: 10.1016/j.energy.2016.01.070

[16] Moreno T.S., et al. (2016). Solar resource assessment in Seville, Spain, statistical characterization of solar radiation at different time resolutions, Solar Energy, Vol. 132, pp. 430-441. DOI: $\underline{10.1016 / j . s o l e n e r .2016 .03 .032}$
[17] Rovense F., Perez M.S., Amelio M., Ferraro V., Scornaienchi N.M. (2017). Feasibility analysis of a solar field for a closed unfired Joule-Brayton cycle, International Journal of Heat and Technology, Vol. 35, Special Issue 1, pp. S166-S171. DOI: $\underline{10.18280 / \text { ijht.35Sp0123 }}$

[18] Cucumo M., Ferraro V., Kaliakatsos D., Crea F., Tassone F., Mumoli A., Mele M. (2017). Thermodynamic analysis of a prototype indirect screw drier for aggregates and recycled mineral aggregates, International Journal of Heat and Technology, Vol. 35, Special Issue 1, pp. S427-S434. DOI: $\underline{10.18280 / \text { ijht. } 35 \mathrm{Sp} 0158}$ 